\title{
A consumidora empoderada: publicidade, gênero e feminismo
}

\section{Lígia Campos de Cerqueira Lana}

Doutora; Pontifícia Universidade Católica do Rio de Janeiro, Rio de Janeiro, RJ, Brasil

ligialana@gmail.com

\section{Carla Basílio de Souza}

Bacharela; Universidade Federal do Rio de Janeiro, Rio de Janeiro, RJ, Brasil

carlabasilio.ds@gmail.com

\section{Resumo}

Desde meados dos anos 1980, anúncios publicitários, quando elaboram representações de gênero, incorporam ideais associados, em linhas gerais, ao feminismo: liberdade, autonomia e poder. Neste artigo, apresentamos um estudo de caso do anúncio Homenagem, das Lojas Marisa, alvo de intensos protestos por parte do Femen Brasil e outros coletivos feministas. Diante das manifestações, a marca respondeu por meio de um vídeo, mas manteve o posicionamento da campanha, o que desagradou ainda mais as presumidas consumidoras. Descrevemos a estrutura narrativa do anúncio publicitário; analisamos a cobertura midiática do caso e os argumentos das manifestantes, com o objetivo de examinar as contradições e as ambiguidades tanto da promoção do consumo, quanto da lógica da crítica pós-feminista hoje. As conclusões da pesquisa mostram em que medida os movimentos feministas produziram um debate público relevante, ao apontar a presença das desigualdades de gênero na mídia e ao mobilizar uma discussão sobre corpo, saúde e doença das mulheres.

\section{Palavras-chave}

Publicidade. Gênero. Feminismo. Pós-Feminismo. Corpo feminino.

\section{Introdução}

Em 2004, a empresa Unilever lançou a campanha mundial Dove Real Beleza. Em anúncios publicitários na mídia impressa e na televisão, mulheres comuns, felizes e confiantes, vestidas com peças íntimas, celebravam a verdadeira beleza feminina. Nos filmes 
e imagens promocionais, as protagonistas aparentavam diversidade física, étnica e etária. Além de posicionar a marca e aumentar as vendas da linha Dove, a estratégia da campanha era promover uma reflexão: os anúncios contestavam o padrão da beleza feminina na mídia, excludente e inalcançável, que não correspondia aos ideais das mulheres contemporâneas. No relatório da pesquisa que orientou o conceito da campanha, produzido pela empresa de marketing StrategyOne, junto com Nancy Etcoff, da Harvard Medical School, e Susie Orbach, da London School of Economics, denunciou-se um conceito manufaturado, limitador e inautêntico de beleza feminina em vigor na mídia impressa e audiovisual.

Dove Real Beleza, sucesso de audiência que se mantém no ar há mais de doze anos, em diversos países, sugeria que a beleza autêntica e singular, não circunscrita às formas padrões divulgadas na mídia, seria uma crescente aspiração feminina. 0 posicionamento da Unilever em Dove Real Beleza ressalta a moral da autenticidade, característica da sociedade moderna em que a configuração das identidades baseia-se no contato consigo mesmo. (TAYLOR, 1991). Consumidoras acima do peso, com sardas e manchas, de baixa estatura, negras e idosas encontrariam, em Dove Real Beleza, referências para refletir sobre si, a partir de personagens diferentes do padrão dos anúncios de produtos de beleza - altas, magras, brancas e jovens. Importantes questões de gênero implicadas no ideal moderno de autenticidade foram, também, tratadas pela mensagem da campanha.

Desde a década de 1960, no bojo de reivindicações políticas e sociais, ativistas feministas criticam a publicidade, denunciando a humilhação e a objetificação da mulher. Protestos notórios, como a manifestação contrária ao Miss America, em 1968, dirigiam suas principais críticas à publicidade, considerada o meio de comunicação mais nocivo para as mulheres. Batalhas semióticas de intervenção com grafite e sticker, em anúncios publicitários considerados ofensivos, surgiram também naquele momento (GILL, 2007). Em 1963, o best-seller Mística feminina, de Betty Friedan, foi decisivo para a sistematização da crítica feminista à mídia, ao propor que a publicidade seria a principal responsável pela criação de mitos opressores. Os argumentos da autora, debatidos mundialmente, sustentavam que a imagem da mulher na publicidade servia à promoção e ao consumo de eletrodomésticos, itens de limpeza e outros produtos para o lar. As representações publicitárias expressavam que, adquirindo esses bens, mulheres alcançariam sua verdadeira vocação: construir uma vida doméstica bem-sucedida e tornar-se uma heroína do lar (FRIEDAN, 1971). 
No final da década de 1980, observam-se os primeiros esforços da mídia para incorporar, nos anúncios publicitários, as críticas do movimento feminista. De acordo com Rosalind Gill (2007), inúmeras pesquisas acadêmicas publicadas nos anos 1990 constataram a paulatina mudança da imagem da mulher na publicidade: elas passaram a ser retratadas no ambiente de trabalho, aparentando ter mais autoridade e autonomia que nas décadas anteriores. Naquele momento, a crescente presença do discurso feminista na vida social não poderia ser mais ignorada por narrativas que construíam conceitos de feminilidade e masculinidade, família e intimidade, emoções e projetos de vida. As reivindicações feministas tornaram-se, como argumentam Robert Goldman, Deborah Heath e Sharon Smith (1991), uma commodity da publicidade. Os anúncios publicitários passaram a incorporar, assim, argumentos relacionados ao poder, à liberação e à autoestima das mulheres. Emergiu uma publicidade mais reflexiva, que reposicionou os modos de endereçamento dos produtos às consumidoras e, também, o olhar masculino para o corpo feminino.

Os anúncios publicitários passavam a sugerir que mulheres tinham consciência das desigualdades de gênero, como no conhecido outdoor da marca Wonderbra, de 1995, que trazia a modelo Eva Herzigova confiante de seu corpo e da avaliação de sua aparência (MCROBBIE, 2004). A campanha Dove Real Beleza, portanto, indicaria o amadurecimento da incorporação das reivindicações feministas na publicidade no início do século XXI. A Unilever não promoveu apenas uma campanha publicitária, Dove Real Beleza financiou pesquisas e livros, promoveu workshops e mobilizou a reflexão intelectual acerca do empoderamento da mulher, por meio da reivindicação da beleza verdadeira e da crítica à opressão dos tradicionais padrões da publicidade.

0 revigoramento do discurso feminista na publicidade, analisado como commodity, é sempre um recurso para conquistar a atenção do mercado. A campanha Dove Real Beleza estimula a reflexão sobre o corpo feminino, sem perder de vista seu maior objetivo: aumentar as vendas da marca. As reivindicações feministas na publicidade são, portanto, apresentadas como proclamação de liberdade para o consumo, atitude e sinal de estilo da mulher antenada. Afastado de ideais coletivos, o feminismo aparece na publicidade de maneira domesticada, contendo sua crítica social e criando uma protagonista empoderada para realizar desejos individuais. Nos últimos anos, a literatura da área demonstra que essa recente justaposição de fronteiras, outrora bem delimitadas, entre mídia e feminismo 
aumenta a força do pós-feminismo, marcado pela desarticulação dos ideais coletivos dos movimentos dos anos 1960 (GENZ; BRABON, 2009; GILL, 2007; BROOKS, 2003).

Neste artigo, analisamos a campanha publicitária Homenagem, promovida pela rede varejista Marisa para sua coleção de verão em 2012¹. No filme-publicitário de 30 segundos, divulgado na televisão aberta, uma mulher, depois de enfrentar uma dieta rigorosa, anuncia estar pronta para a estação. Magra, feliz e vitoriosa, ela desfila sob olhares masculinos e femininos, vestida com roupas frescas, curtas e decotadas, próprias ao clima do verão. Insatisfeitas com a mensagem da campanha, ativistas protestaram nas portas das lojas de Belo Horizonte, de Palmas e do Rio de Janeiro. As manifestações intituladas Vou pelada, mas não vou de Marisa foram noticiadas na imprensa. Em resposta aos protestos, a rede varejista lançou um vídeo no YouTube, propondo uma conversa franca com a Marisa, em que, aparentemente, buscava incorporar em seu discurso as reivindicações feministas. A estratégia da empresa, contudo, foi desastrosa: apesar de sinalizar que reconheceu a existência das manifestações, Marisa manteve o posicionamento da marca, o que provocou novos protestos na internet.

O estudo do caso revela que houve o aumento da insatisfação das presumidas consumidoras. Mostraremos, com a análise do caso, que as articulações entre feminilidade, feminismo e publicidade expõem contradições e ambiguidades ideológicas tanto da promoção do consumo, quanto da lógica da crítica feminista hoje. Da mesma maneira, observaremos possíveis assimetrias de gênero e ocorrência de estereótipos, bem como a ocorrência de dissonâncias nesses discursos. Como analisa Joan Scott, o termo "sexo" é usado para naturalizar as diferenças entre homens e mulheres, e esse tipo de avaliação deve ser problematizada, já que a masculinidade e a feminilidade não são inerentes ao ser humano, mas sim fruto de construções sociais (SCOTT, 1989). Embora, os estudos de gênero tenham questionado, nas últimas décadas, o determinismo biológico (que associa os indivíduos a padrões naturais de comportamento), redefinindo processos de subjetividade e identidade e contribuído para que as mulheres conquistassem direitos, as discussões que envolvem as representações do feminino na mídia massiva ainda podem avançar.

Nesse sentido, os ambientes virtuais mostram-se como um espaço relevante para a área, uma vez que têm propiciado discussões dinâmicas e eloquentes, que rejeitam, por exemplo, um caráter fixo e a naturalização dos gêneros feminino e masculino. Tais debates

\footnotetext{
10 material empírico aqui em análise foi, inicialmente, objeto da monografia de conclusão de curso "De mulher para mulher": representações de gênero em campanhas da varejista Marisa e sua repercussão em ambientes on-line (SOUZA, 2015).
} 
visam deslocar essa "[...] construção hierárquica, em lugar de aceitá-la como real, como óbvia ou como estando na natureza das coisas." (SCOTT, 1989, p. 19).

Em nosso estudo, articulamos dados específicos da campanha da Marisa a uma compreensão crítica do pós-feminismo, muito em voga na mídia de massa, em que mulheres são individualmente responsabilizadas pela construção de uma vida bem-sucedida. 0 artigo, portanto, conjuga o estudo de caso a um enquadramento analítico que busca determinar em que medida os receituários de consumo da publicidade brasileira ecoam e dialogam com a vida social, contribuindo para a configuração de valores, conflitos e ambiguidades experimentadas na cultura hoje.

A metodologia articula o posicionamento da empresa e a reação de consumidores, predominantemente mulheres, nos ambientes virtuais. Nosso recorte analítico é composto:

a) vídeo publicitário da campanha Homenagem (2012), divulgado na televisão aberta;

b) vídeo-resposta da empresa, divulgado no Facebook;

c) três matérias jornalísticas que noticiaram manifestações contra a marca;

d) fotografias das manifestações publicadas pelo grupo feminista Casa 8 de Março;

e) texto de Riva Telari (2012) publicado no blog Escreva Lola Escreva;

f) texto da petição "Laís como garota propaganda", divulgado no site Activism.com.

Além disso, a metodologia de análise orienta-se por um olhar genealógico, que busca identificar as origens das relações de poder trazidas no material coletado. (FOUCAULT, 1987) $)^{2}$.

\section{Uma inconveniente homenagem aos alimentos}

0 filme-comercial Homenagem (2012), transmitido pela primeira vez em 16 de outubro de 2012, tem duas partes. Na primeira parte, um plano em close apresenta o rosto de uma mulher deitada, com olhar perdido e um sorriso discreto. A modelo, desconhecida, é magra, branca e tem cabelos longos. 0 enquadramento da imagem estende-se e revela que ela está em um quarto organizado e bem decorado. Em câmera lenta, ela agora caminha com o olhar fixo em direção ao lado direito do quadro. Uma voz feminina calma, em off, acompanhada por uma trilha sonora orquestral, anuncia: "Esta é uma homenagem a todos vocês que me ajudaram a chegar aqui." Em seguida, em close up, aparecem a boca e o nariz

\footnotetext{
${ }^{2}$ Agradecemos pelas críticas e sugestões dos avaliadores e editores da Revista Intexto, que contribuíram para o aprimoramento da exposição da metodologia de nosso trabalho.
} 
da mulher, que morde uma folha de couve enquanto respira ofegante. A voz em off prossegue: "A todos os chuchus que eu comi este ano.". Em super close up, surgem as mãos da mulher abotoando um short cor-de-rosa. Deitada novamente, ela segura um espelho oval e admira seu rosto no espelho. Na tela, surge o preço do short, $\mathrm{R} \$ 39,99$. A locução, em off, continua: "[...] aos pepinos fatiados, baby cenouras e quinoas que acalmaram meus momentos de ansiedade.". Cenouras, alface e quinoa são exibidas em close. Apesar de afirmar que os alimentos a acalmaram, as imagens desmentem a informação: assentada no sofá, a modelo bate os dedos impacientemente; de pé, ela dá muitos saltos, sacodindo as mãos nervosamente; por fim, morde um lápis. Dois pequenos balões decorativos voam calmamente, quando, repentinamente, um deles estoura, deixando escapar uma fumaça branca. Em close, os pés inquietos da modelo, com unhas pintadas de vermelho, aparecem em cima de uma balança. 0 resultado gira em torno dos 40 ou 50 quilos.

Figura 1 - Imagem da campanha Homenagem



Fonte: Homenagem (2012).

Em seguida, na segunda parte do filme, a mulher aparece caminhando em um lugar ensolarado, rodeada por palmeiras. 0 preço da blusa que ela está usando é apresentado. Jogando o chapéu que usa no chão, ela prossegue, agora com a voz animada: "Uma justa homenagem às leguminosas e às sopas ralas que fizeram minhas refeições menos alegres, mas que farão meu verão mais feliz." Um plano em close mostra um sorvete derretendo e cupcakes confeitados com expressões tristes. Ao afirmar - "Farão meu verão mais feliz." - a mulher aparece de biquíni, andando em direção a uma piscina. Preços de outras peças são 
apresentados. Embora, o foco continue sendo a mesma personagem, o cenário é completamente diferente: ela saiu do recolhimento para a exposição; de um ambiente mal iluminado para um lugar ensolarado, com várias outras pessoas brincando e se divertindo. (SOARES-CORREIA, 2013).

Figura 2 - Imagem da campanha Homenagem

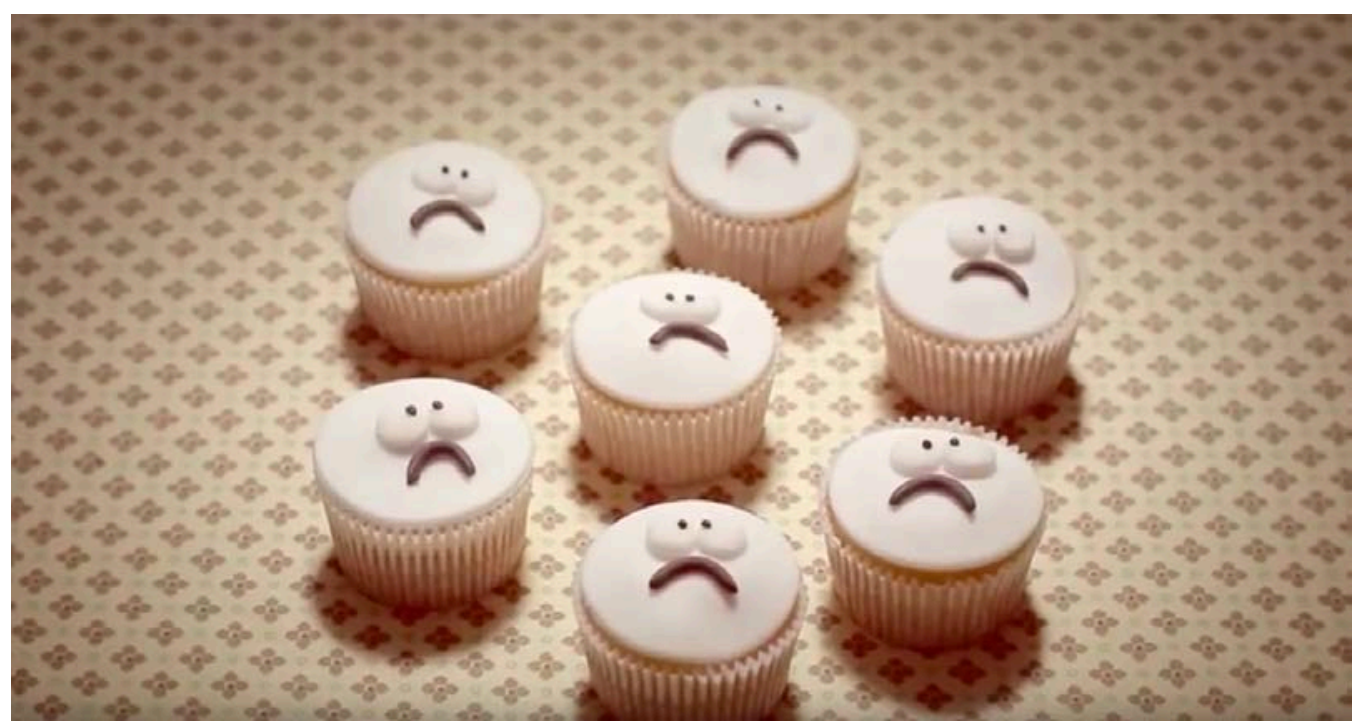

Fonte: Homenagem (2012).

Não aparentando a ansiedade da primeira parte do filme, ela ajeita sorridente o cabelo, enquanto outras mulheres a admiram, sugerindo estarem com inveja. Um grupo de três homens assentados em uma mesa a observam - um deles chega a se virar para trás - e parecem aprovar seu visual. A expressão da mulher também se modifica: o sorriso discreto e o olhar perdido da primeira parte são substituídos por um sorriso aberto para os outros, sugerindo que ela está feliz e quer verdadeiramente mostrar isso por meio da postura altiva e confiante que atrai olhares de homens e mulheres.

No país onde, há poucas décadas, foi necessário implementar uma Ação da Cidadania Contra a Fome, a mulher bela da Marisa é magra ${ }^{3}$. Ao contrário da campanha de Dove, em que a beleza implica diversidade, a campanha da loja brasileira vincula o corpo belo ao emagrecimento, alcançado pelo esforço individual, ao seguir uma dieta alimentar restritiva. No epílogo, a mulher passa em frente à câmera e a narradora diz “Coleção alto verão Marisa.

\footnotetext{
${ }^{3}$ Ação da Cidadania contra a Fome, a Miséria e pela Vida, criada em 1993, por Herbert de Souza estimulou a formulação de programas governamentais como Comunidade Solidária, em 1995, por Fernando Henrique Cardoso, e Fome Zero, por Luís Inácio Lula da Silva.
} 
Tudo vale a pena pra viver bem o verão.". Dentro da água, ela aparece sorrindo para câmera. O comercial termina com a tela em rosa-choque, cor da empresa, e o slogan, escrito em cor branca "De mulher pra mulher: Marisa".

A historiadora Denise Sant'anna (2012) indica que recomendações para manter a silhueta feminina esguia não são recentes. No início do século XX, diversas revistas, ancoradas em ideais sanitários modernos da regulação do corpo saudável, aconselhavam sobre dietas nutritivas, quase sempre direcionadas às mulheres: "[...] por um lado, a mulher desnutrida representava a constituição de uma raça fraca [...] por outro, era preciso muito cuidado para não atribuir-lhe um caráter excessivamente másculo." (SANT’ANNA, 2012, p. 194). 0 descuido com as formas corporais poderia resultar em falta de atrativos para o sexo oposto.

Assim, a censura ao sobrepeso ganhou força no início do século XX. Como mostra George Vigarello (2010), a gordura corporal passou a ser controlada, a partir daquele momento, por balanças domésticas e espelhos para a observação do corpo inteiro. A medicina lançou a associação entre peso e altura e a classificação mais precisa dos tipos de obesidade. Além disso, a descoberta da energia dos alimentos fez surgir uma ciência da alimentação, vulgarizando regimes e terapias de emagrecimento. Desde aquele momento, a personagem principal do debate sobre o controle da gordura foi a mulher. Nos Estados Unidos, as Gibson Girls, que tiveram ápice de popularidade na década de 1910, eram altas e magras, com a cintura definida por espartilhos. 0 combate à gordura corporal era "[...] sobretudo feminino. Antes do aparecimento das Gibson Girls, as imagens das jovens belas publicadas na imprensa norte-americana e na literatura erótica exibiam uma variedade de formas físicas maior do que aquela vigente depois de 1900." (SANT'ANNA, 2012, p. 196).

Naquele mesmo período, no Brasil, Denise Sant'anna (2012) argumenta que, ainda que anúncios de medicamentos para engordar - não parecer fraco e raquítico, características associadas à pobreza - fossem mais numerosas que os de remédios para emagrecer, houve um aumento de anúncios para cintas modeladoras femininas e a valorização de atividades físicas. Desde então, aprofundou-se a associação entre alimentação saudável, corpo magro e saúde, o que indica a grande variedade de dietas surgidas nas últimas décadas, como Atkins, Dukan, Dash, Detox, Funcional, Low Carb, entre tantas outras. A correta ingestão da comida consolidou seu poder de transformar a vida dos indivíduos, tornando-se parte indissociável da sua identidade. 
Há muito sabemos que "somos o que comemos". Mas, atualmente, somos levados a jamais esquecer que podemos ser tudo o que queremos, desde que as mudanças alimentares em voga façam parte da nossa rotina. $\mathrm{Ou}$ seja, por meio da comida pode-se, por exemplo, mudar a aparência corporal, transformar o estado emocional e reinventar cotidianamente a própria subjetividade. Como se fosse possível aplicar a regra: "dizes o que comes e eu te direi quem és e o que serás", ou seja, por meio do que é ingerido diariamente é possível modificar a intimidade de cada um. (SANT'ANNA, 2003, p. 42).

De acordo com o comercial Homenagem (2012), se a mulher come legumes e verduras, ela é infeliz porque os alimentos são ruins; se ela, contudo, come irrestritamente cupcakes e sorvetes ela não conseguirá emagrecer, o que também trará infelicidade. A personagem, então, decide passar pelo desgosto do controle vigilante de sua alimentação: ansiosa, resguarda-se em um ambiente fechado e solitário até alcançar o peso adequado, matematicamente atestado pela balança. A condição de inadequação corporal e a dieta causavam incômodo, nervosismo e solidão. Com a recompensa do emagrecimento, ela sentese autorizada a deixar o quarto sombrio e passear alegre em um local ensolarado e cheio de pessoas. A personagem inebria-se consigo mesma e sorri triunfante, como alguém que não acredita no que vê; tudo parece novo, como se ela estivesse acordando de um sonho ou sonhando acordada. "Tudo vale a pena para viver bem o verão.": a frase, conclusão da narrativa, relaciona o absoluto e incondicional esforço para emagrecer a um estado de espírito positivo.

Os exageros do filme representam as inúmeras mulheres que rejeitam suas formas corporais e desenvolvem transtornos alimentares, como anorexia e bulimia, doenças tipicamente femininas, que podem levar à morte. Os impactos da severa restrição alimentar da protagonista do filme foram criticados na queixa de consumidores ao Conselho Nacional de Autorregulamentação Publicitária (Conar). Na síntese da denúncia, divulgada no site da entidade, as reclamantes teriam alegado que o anúncio estimularia "[...] preconceito contra mulheres gordas e apologia da anorexia." (RIOS, 2012). O filme incentivaria, assim, distúrbios alimentares severos, não fazendo nenhuma menção aos benefícios da prática de esporte, por exemplo, que auxiliam no emagrecimento saudável. No parecer do Conar, contudo, as diferenças entre alimentação saudável e transtornos psicológicos associados à comida não foram levados em consideração: "Já vi inúmeras reclamações sobre publicidade que estimularia a má alimentação, o excesso de doce, sódio e gordura. Mas reclamar sobre sua ausência de fato me surpreendeu." A relatora Daniela Gil Rios (2012) emitiu o parecer pelo arquivamento da denúncia, aprovado com unanimidade, justificando que a campanha 
seria "bem humorada" e refletiria uma "conduta positiva" e "sacrifício pessoal em alimentarse de forma saudável".

A homenagem irônica da protagonista aos legumes e vegetais expõe papéis sociais de gênero relacionados à alimentação e aos padrões corporais. Como notou, pioneiramente, Erving Goffman (1979), a publicidade reflete sentidos sociais de feminilidade, atualizando e estabelecendo um vocabulário imagético do ser mulher. Para ser visto de maneira satisfatória, o corpo feminino obedece às regras da feminilidade expostas nos anúncios, ligadas ao consumo e ao esforço - físico, mental e financeiro - para chegar próximo a ele: usar maquiagem, cuidar dos cabelos e da pele e retirar os pelos do corpo.

No histórico da commodity do feminismo na publicidade, os anúncios incorporaram, muito recentemente, a crítica aos padrões tradicionais da beleza feminina, aspecto que trouxe o pioneirismo da campanha Dove Real Beleza. Em O mito da beleza, Naomi Wolf (1992) mostrou que a consolidação da crítica ao anjo do lar, promovida pela denúncia da mística feminina e pela crescente entrada das mulheres no mercado de trabalho, a partir dos anos 1970, fez com que o corpo da mulher se tornasse mais vulnerável às desigualdades de gênero. 0 mito da beleza, para a autora, ganhou papel privilegiado no exercício do poder institucional dos homens.

A ocupação com a beleza, trabalho inesgotável porém efêmero, assumiu o lugar das tarefas domésticas, também inesgotáveis e efêmeras. Como a economia, a lei, a religião, os costumes sexuais, a educação e a cultura foram forçados a abrir um espaço mais justo para as mulheres, uma realidade de natureza pessoal veio colonizar a consciência feminina. Recorrendo a conceitos de "beleza", ela construiu um mundo feminino alternativo, com suas próprias leis, economia, religião, sexualidade, educação e cultura, sendo cada um desses elementos tão repressor quanto os do passado. (WOLF, 1992, p. 20).

Desde a publicação desta obra, a indústria cosmética desenvolveu incontáveis novos recursos para a continuidade da construção do mito da beleza feminina. Nesse sentido, para estimular o consumo, a commodity feminista nos anúncios de produtos de beleza associa-se à independência, à liberdade individual e ao autocontrole, como se buscar o corpo belo fosse sinal de atitude da mulher moderna. "Significados de escolha e liberdade individual associam-se a imagens sensuais, em que mulheres aparentemente escolhem ser vistas como objetos sexuais, porque isto se adapta a seus interesses de libertação." (GOLDMAN; HEATH; SMITH, 1991, p. 338). Em 1986, por exemplo, a campanha Não me odeie porque eu sou bonita (PANTENE, 1986), que popularizou a marca Pantene, apregoou a ostentação beleza feminina 
como estratégia legítima das disputas da vida social. A protagonista do anúncio, a modelo Kelly Le Brock, celebrizada pela campanha, personificou a mulher segura, autoconsciente e bem-humorada, que encara a beleza como resultado de sua postura altiva no mundo. A partir do final dos anos 1980, a mulher não é mais representada na publicidade como o imaculado anjo do lar, mas permanece bonita e encantadora, responsável pelo seu bemestar e por um ambiente feliz e agradável ao seu redor. Passa a existir, assim, uma contraditória associação, típica da sensibilidade pós-feminista, entre feminismo e feminilidade. A entrada das mulheres no mercado de trabalho e a conquista de direitos sociais são traduzidas na publicidade de produtos de higiene e beleza como liberdade e autonomia para alcançar o corpo belo.

A publicidade direcionada à mulher, depois dos anos 1980, avalia quais ganhos do feminismo foram conquistados por seu público-alvo, consumidoras multifacetadas por classes, etnias, crenças e idades. A pergunta ampla "O que as mulheres querem?" foi substituída por indagações mais específicas sobre a concepção de feminilidade para a mulher visada na audiência (GOLDMAN; HEATH; SMITH, 1991).

No caso da rede varejista Marisa, suas estratégias dirigem-se a mulheres entre 20 e 35 anos de idade da classe C. De acordo com o Instituto Brasileiro de Executivos de Varejo e Mercado de Consumo (Ibevar), a Marisa é a maior rede de lojas especializada em moda feminina e moda íntima feminina do Brasil ${ }^{4}$. Na atualidade, a empresa tem 388 lojas espalhadas pelas cinco regiões do país. Das 12 funções da Diretoria e do Conselho Administrativo da empresa, apenas três são realizadas por mulheres (MARISA, 2017). No site da empresa, a classe $\mathrm{C}$, seu público-alvo, é definida como tendo renda familiar mensal média entre $\mathrm{R} \$ 1.829,00$ e R \$3.379,00 e, de acordo com as projeções divulgadas por Marisa, de 2004 a 2011, a participação dela sobre a população brasileira cresceu 36\%, aumento de 27 milhões de pessoas.

Ao indicar que a ansiedade de uma dieta restritiva pode ser recompensada pelo emagrecimento, Marisa, possivelmente, deseja alcançar mulheres incrédulas da existência de variados tipos de beleza. ${ }^{5}$ A mulher projetada no anúncio de Marisa regula sua

\footnotetext{
${ }^{4}$ Marisa é, também, uma das maiores redes de lojas de departamento de vestuário misto (feminino, masculino e infantil) do país, atrás de C\&A, Riachuelo, Casas Pernambucanas e Lojas Renner, que são consideradas lojas mistas, embora a maior parte dos anúncios seja destinada ao público feminino. Apenas Marisa Ampliada tem roupa para toda a família (INSTITUTO..., 2015).

${ }^{5}$ Em 2015, Marisa lançou, pela primeira vez, anúncios com mulheres acima do peso, a primeira campanha plus size de uma rede varejista nacional. A companhia lançou um catálogo especial plus size, estrelado pela modelo internacional Fluvia Lacerda. Contudo, as imagens de Fluvia não foram as únicas naquela coleção: houve, também, as tradicionais fotografias com modelos magras, jovens e brancas, divulgadas no site da empresa.
} 
alimentação e quer ser magra; o final feliz da narrativa enfatiza o consumo dos produtos de verão, shorts, regatas e roupas de banho, associando consumo e contentamento do corpo emagrecido, alcançado por seu esforço pessoal. Na concepção da mensagem da campanha, as críticas feministas ao mito da beleza, portanto, não foram consideradas relevantes para a consumidora da Marisa. Por que então a campanha foi alvo de protestos? Os anúncios publicitários buscam promover o consumo de produtos, mas são também, eles mesmos, consumidos como narrativas. "O consumo de anúncios não se confunde com o consumo de produtos. Podemos até pensar que o que menos se consome num anúncio é o produto. Em cada anúncio, vendem-se estilos de vida, sensações, emoções, visões de mundo, relações humanas, sistemas de classificação." (ROCHA, 2010, p. 32). As roupas de verão da Marisa, em 2012, foram consumidas por aquelas que desejaram e puderam comprar; a narrativa do anúncio distribuiu-se na televisão aberta, de maneira massiva, no horário nobre.

\section{3 "Vou pelada, mas não vou de Marisa"}

Realizada a descrição do filme Homenagem (2012), buscamos aprofundar a compreensão da má repercussão da campanha da varejista Marisa. Passamos, assim, ao exame de diversos elementos discursivos - matérias jornalísticas, fotografias, vídeos, comentários no Facebook, argumentos de uma petição on-line, entre outros. A coleta do material empírico acompanhou a reverberação midiática do caso, observada por meio da internet. Os textos analisados foram publicados no período do acontecimento, entre novembro e dezembro de 2012.

Buscamos e selecionamos, inicialmente, o material jornalístico que noticiou, na mídia massiva, as manifestações em diferentes cidades do Brasil. Em seguida, discutimos as informações trazidas pelo artigo da ativista Riva Telari (2012), coletado no blog Escreva Lola Escreva. Os diferentes materiais analisados implicam perspectivas distintas para a leitura do caso. Nossos operadores analíticos buscam confrontar as visões críticas da campanha, encampadas, especialmente, nos comentários do vídeo-resposta da Marisa trazidos pelo texto de Telari (2012), com a perspectiva da marca, que busca estratégias para um diálogo difícil com o público digital.

A avaliação dessa troca discursiva confronta o padrão da mulher projetada pela Marisa (e a inabilidade da marca nos ambientes virtuais) e os questionamentos trazidos pela repercussão do caso. Como esboçado na seção anterior, os discursos pós-feministas, que exaltam a mulher autônoma e responsável por alcançar uma vida bem-sucedida, dentro de 
padrões corporais e estéticos bem definidos, são articulados como commodities pela publicidade - aspecto questionado na repercussão do caso e aqui analisado.

No dia 21 de outubro de 2012, o grupo feminista Casa 8 de Março ${ }^{6}$ realizou um ato "silencioso e pacífico" em frente a uma das filiais da loja Marisa em Palmas. Segundo a página Feministas do Cariri, o protesto durou cerca de 20 minutos até que as ativistas foram convidadas, pelos seguranças, a encerrar a manifestação. (FEMINISTAS..., 2012). Na fotografia do evento, os cartazes afirmavam: "Vou pelada, mas não vou de Marisa”, "Contra a mídia machista" e "Nosso corpo, nosso território".

Figura 3 - Manifestação do Grupo Casa 8 de Março
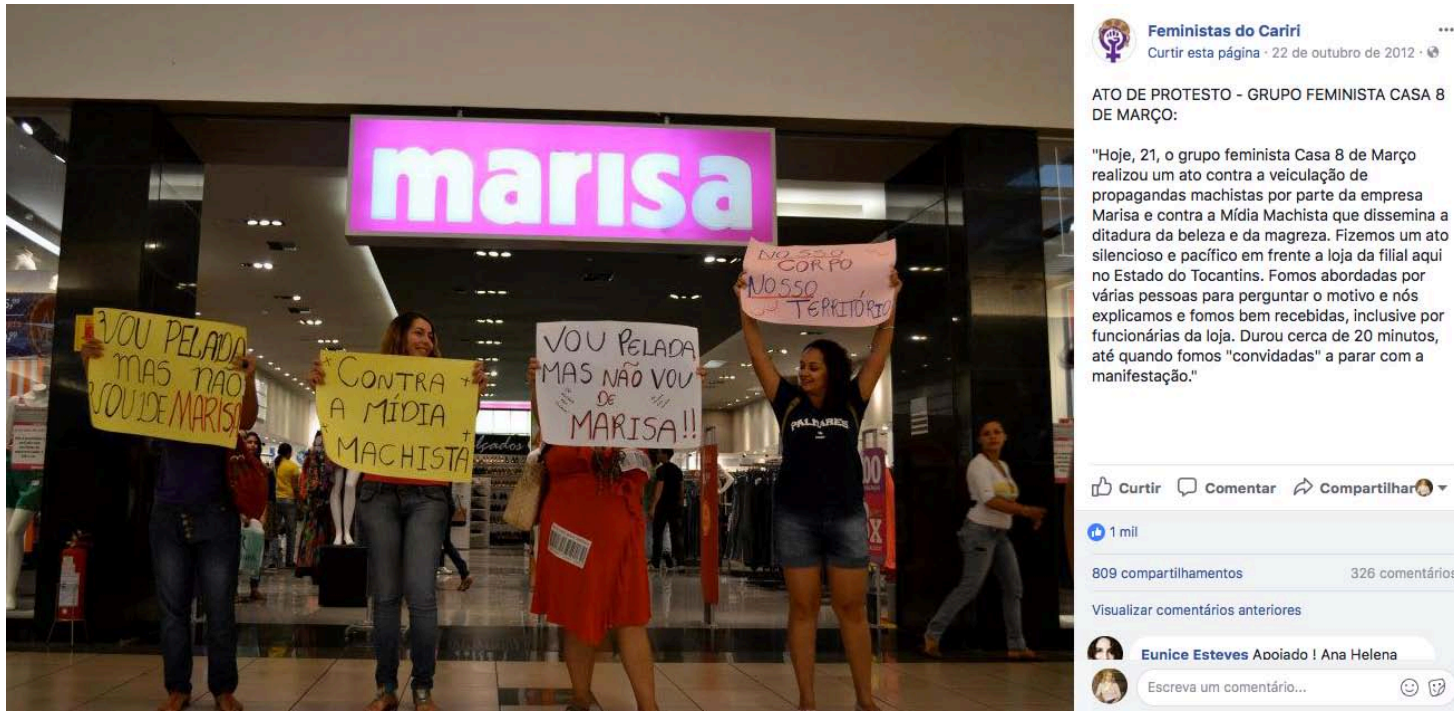

Fonte: Feministas... (2012)

Em seguida, no Rio de Janeiro, houve quatro protestos em diferentes partes da cidade: Copacabana, Meier, Tijuca e Centro. Com menos cobertura jornalística, os atos foram organizados pelo Facebook e, além do anúncio Homenagem, também criticavam outras duas campanhas da empresa, que não estavam mais no ar.

Em Belo Horizonte, no dia 11 de novembro de 2012, ativistas do grupo Femen, de topless, com corpos pintados e coroas de flores na cabeça, entraram em uma loja Marisa no centro da cidade, derrubaram roupas das araras e quebraram alguns manequins. As imagens, divulgadas em grandes portais brasileiros, como Terra (FONTES, 2012a), Uol (FONTES, 2012b) e G1 (D'ALAMA, 2012) mostravam as manifestantes, a loja, os manequins

\footnotetext{
${ }^{6}$ Grupo feminista de Palmas, Tocantins, que organiza, especialmente, cursos de formação e palestras em busca da mobilização
} em prol das mulheres. 
quebrados e os cartazes: "Foda-se a ditadura da beleza", "Não somos Barbies, somos mulheres", "Não troco minhas estrias pela couve da Marisa". O Femen elevou, portanto, o capital de visibilidade do caso. A colunista Heloísa Tolipan (2012), no Jornal do Brasil, divulgou a justificativa apresentada pelo Femen para a realização do ato. "Sim, foi vandalismo, mas um vandalismo simbólico, que demonstra o repúdio pelas atitudes e comerciais que propagam o desrespeito à diversidade humana e fazem apologia à ditadura da beleza.".

Nas manifestações em Palmas, Rio de Janeiro e Belo Horizonte, apesar das diferentes estratégias, as ativistas protestaram por motivos semelhantes: elas mostravam seu descontentamento com a mensagem publicitária da rede varejista Marisa e reivindicavam o respeito ao corpo feminino. Diante dos protestos, a Marisa propôs em sua página no Facebook - intitulada Vou de Marisa - um diálogo com o público. Para isto, a empresa lançou o vídeo Conversa. (VOU..., 2012). Encarando diretamente a câmera, uma mulher branca e magra, assentada em um sofá, pergunta: "A gente pode falar de mulher pra mulher e fazer de conta que não tem ninguém ouvindo? É que assim fica mais fácil de assumir: a gente não é fácil não!". A frase de abertura sugere que, naquele vídeo, a Marisa e as consumidoras poderiam retomar a intimidade e a cumplicidade, abaladas pelo descontentamento com a campanha Homenagem (2012). Enquanto balança a cabeça negativamente, ela prossegue: "[...] mulheres são seres complexos, cheias de questões, nada decifráveis[...]”. Agora com os cabelos presos, ela diz: "[...] cada uma é de um jeito e quem tenta rotular acaba falando bobagem. Quer ver?". Ao longo de todo vídeo, a protagonista aparece em diferentes ambientes domésticos. A consumidora com quem a Marisa deseja conversar, portanto, transita com desenvoltura da cama à mesa, mas não habita a esfera pública. Deitada, ela afirma: "Tem mulher que vive pros outros: pro marido, pros filhos, abdica da carreira e tudo bem.". Em uma varanda, com uma piscina ao fundo, ela prossegue: "Na outra ponta, tem aquela que apostou todas suas fichas no sucesso profissional, que se é feliz assim, tá tudo lindo também.". Em uma sala, ela diz: "No meio do caminho tem aquela que conseguiu equilibrar carreira e família, palmas pra ela também.".

A mulher da Marisa pode alcançar a felicidade por meio de, pelo menos, três caminhos: viver para a família, alcançar sucesso profissional e equilibrar família e carreira. Não haveria uma fórmula padrão para a vida plena, desde que as próprias escolhas fossem feitas com liberdade. 0 vídeo busca estabelecer uma ponte entre feminilidade e feminismo, erguida pela autoestima, liberdade e aceitação das singularidades da trajetória individual de 
cada mulher. Com uma sensibilidade pós-feminista (GILL, 2007), respondendo às manifestantes, a Marisa mantém a commodity do feminismo como esforço individual, distante de constituir "[...] um meio para superar as forças de opressão - a dominação masculina e o mundo institucional das relações de produção" (GOLDMAN; HEATH; SMITH, 1991, p. 338).

Prosseguindo o vídeo, a personagem aborda, em outro ambiente e vestindo outras roupas, o assunto da campanha Homenagem (2012). "E quando o assunto é padrão de beleza então? Não tem nada menos unânime do que isso". Deitada novamente, ela indaga: "Ditadura da magreza? Siga quem quiser. Formas generosas? Que as tenham que as quiserem.". Em seguida, assentada em um sofá, ela pergunta: "Rugas, cabelos brancos, celulite? Incrível a mulher que não se preocupa com essas bobagens.". A Marisa sugere que não existe "nada menos unânime" do que os conceitos de beleza, porém a protagonista do vídeo segue todos os padrões possíveis: branca, magra e jovem.

A narradora, então, argumenta: “[...]mas também não tem nada de errado com quem quer esconder.". 0 vídeo relativiza qualquer posicionamento acerca dos temas em debate emagrecimento, alimentação, transtornos psicológicos, obesidade e vida saudável. Endereçando-se à terceira mulher (LIPOVETSKY, 2000), a narrativa valoriza uma subjetividade desconectada de questões coletivas.

Se é inegável, em particular, que a imprensa feminina exerce um poder de normalização de massa, ainda assim é preciso não ocultar a outra face de sua ação. Paralelamente a seu trabalho de homogeneização das aparências, a mídia feminina caracteriza-se igualmente por uma obra de valorização da individualidade e da personalidade (LIPOVETSKY, 2000, p. 165).

Ao responder aos protestos, a Marisa assume que os padrões únicos de beleza devem ser relativizados, mas mantém o conceito da campanha Homenagem (2012): a valorização do poder e do esforço individual das mulheres. Na parte final do vídeo, a narradora aparece sucessivamente em todos os ambientes apresentados e concluiu: "O legal de ser mulher é isso: a diversidade. Mas uma coisa todas têm em comum: toda mulher gosta de se sentir bonita. E gosta de receber elogio, sim!". Receber elogios nem sempre é satisfatório; mulheres podem gostar de receber elogio, mas não de qualquer pessoa, em qualquer lugar, a qualquer hora, como vêm advogando inúmeras organizações feministas na crítica à cultura do estupro. A narradora, por fim, diz: "Você não concorda? Ótimo. Porque 
outra coisa que a gente adora é discutir e debater. Apareça aqui e deixe sua opinião.". o link para o site da Marisa surge na tela, e ela conclui: “É pra ser uma conversa sincera mesmo... De mulher pra mulher.".

Na página da empresa do Facebook, entre novembro e dezembro de 2012, a publicação do vídeo recebeu mais de três mil comentários que permanecem disponíveis. (VOU..., 2012). Inicialmente, alguns demonstravam apreço pela marca, enquanto outros faziam críticas e lembravam campanhas controversas lançadas pela empresa naquele ano ${ }^{7}$. Ativistas que discordavam das ações do Femen, em Belo Horizonte, discutiam as estratégias do feminismo no Brasili . Ao longo dos dias, questionamentos e críticas à Marisa tornaram-se predominantes. A maioria das pessoas passou a exigir um pedido formal de desculpas da empresa. Blogs feministas publicaram inúmeros artigos, elevando a visibilidade do caso na internet.

Nos comentários no Facebook, um perfil de nome Laís Canção chamava atenção no debate. Como notado por Riva Telari (2012), em texto publicado no blog Escreva Lola Escreva, de maneira insistente, ela elogiava as campanhas e, ao mesmo tempo, buscava construir um perfil espontâneo: falava sobre sua família, pedia dicas de manicure em Moema, escrevia "Mariza", denotando não ter muito conhecimento sobre a empresa. Ao longo dos comentários, “[...] Laís continuou tentando aparentar naturalidade falando sobre sua vida pessoal (de forma totalmente descabida, já que nenhum usuário estava falando sobre assuntos pessoais ou fugindo do tema como ela estava fazendo) e sempre mantendo uma postura de concordância com a postura da marca." (TELARI, 2012, s.p.). Mostrou não entender termos citados pelas participantes do debate, como cissexismo, concluindo que estava sendo "[...] muito difícil ser engajada hoje em dia.".

Uma das participantes percebeu a incoerência nos comentários de Laís e suspeitou estar diante de um fake. Em seu perfil, não havia publicações no mural e nenhuma fotografia, exceto a figura do perfil - proveniente de um banco gratuito de imagens, encontrado em uma pesquisa no Google por uma das participantes. A foto era estranha: uma mulher, aparentemente grávida, com um revólver em uma das mãos e uma melancia em outra. Ainda que Laís utilizasse pouco o Facebook e não publicasse imagens por ser reservada, é estranho que não tivesse nenhum amigo. A única atividade do perfil era a

\footnotetext{
7 Uma análise mais aprofundada dos comentários foi feita por Carla Basílio Souza (2015). Para este artigo, optamos por selecionar e examinar as trocas discursivas de uma usuária, Laís Canção, que demonstrou ser um fake. Nossa metodologia priorizou discutir posicionamentos que traziam os embates entre o posicionamento da marca, apresentado, de maneira dissimulada por Laís Canção, e a crítica das manifestantes.

${ }^{8}$ As estratégias midiáticas do Femen foram analisadas por Beatriz Batista (2014).
} 
defesa da Marisa. Conforme relatou o blog Escreva Lola Escreva, os comentários feitos por Laís Canção eram curtidos apenas por funcionários da agência AlmapBBDO, responsável pela campanha publicitária. Questionada pelos participantes do debate, a suposta consumidora negou que seria um perfil falso e, em seguida, não fez mais nenhum comentário no tópico. Assim que Laís se retirou do debate, a equipe responsável pelo perfil oficial da Marisa que, até aquele momento, vinha respondendo a um ou outro comentário, também desapareceu. Uma petição irônica, assinada por 215 pessoas no Activism.com, solicitou que Laís Canção se tornasse garota-propaganda da Marisa.

Diante da polêmica anterior com um anúncio excludente que incentivava sacrifícios para obter a magreza, ficamos muito satisfeitas em saber da criação de um canal para comunicação com suas consumidoras. Não pudemos deixar de notar uma consumidora chamada Laís Canção, que na página do Facebook demonstrou fidelidade e um grande apreço pela marca. Laís, que conta com o apoio de vários funcionários da agência, é uma mulher real com dois filhos (Breno e Tiago), que admite estar acima do peso e já tem uma carreira internacional como modelo (como visto em sites internacionais onde encontramos sua foto). Acreditamos que ela é a modelo plus size perfeita para ser a nova garota propaganda desta fase inovadora à qual a empresa se propôs, que traz a diversidade como parte integrante da marca. E de acordo com a sugestão da própria Laís, sugerimos um anúncio com uma guerra de travesseiros. Queremos Laís como garota propaganda! Uma MULHER REAL, MULHER DE VERDADE. Quanto aos boatos maldosos que o perfil de Laís seria um fake criado pela agência para obter falso apoio, os rejeitamos pois não acreditamos que uma agência tão renomada utilizaria de uma técnica tão antiética, utilizando indevidamente a imagem de terceiros para enganar suas consumidoras. (LAÍS..., 2012).

De acordo com nossa pesquisa, não foi possível assegurar que o perfil de Laís Canção tenha sido criado pelos responsáveis da página ou pela AlmapBBDO. De toda maneira, a posição da empresa foi incongruente na condução do caso: se estivesse realmente preocupada em conversar com as consumidoras, a Marisa teria ignorado a discussão sobre o perfil falso e continuado a responder os participantes. Houve uma inabilidade da estratégia do marketing digital da Marisa para propor e lidar com situações nos ambientes virtuais. Ao abandonar o debate, a empresa desistiu do plano que ela mesma elaborou, assumindo que a estratégia foi equivocada e infrutífera. 


\section{Considerações finais}

O desfecho pode sugerir que a Marisa avaliou que suas consumidoras não seriam as ativistas mobilizadas nos protestos, tornando relativo o impacto negativo do caso à imagem da empresa. Segundo pesquisa da multinacional InterScience, a marca Marisa, associada ao popular slogan "De Mulher pra Mulher", criado em 1988, pela agência CVS, apresenta forte reputação com o público feminino. Como mostram os gráficos do perfil institucional da empresa, a Marisa tem como público-alvo a mulher brasileira da Classe $\mathrm{C}$, que acompanha os lançamentos da moda e busca adquirir produtos a preços atrativos (MARISA, 2017).

No caso analisado, a feminilidade condicionada ao corpo magro do anúncio Homenagem assemelha-se ao vasto mercado editorial de revistas femininas a preços populares, que trazem, semanalmente, dietas e dicas mirabolantes para emagrecer. Possivelmente, a Marisa presumiu que sua consumidora é leitora dessas revistas. A transformação da protagonista enfatiza a mudança mágica do tipo antes e depois, comum nessas revistas e em outros produtos midiáticos; e oferece elementos simples e rápidos para o discurso de persuasão, próprio à narrativa publicitária. 0 caso expõe as contradições do emagrecimento feminino no país campeão mundial de cirurgias plásticas, mas que, ao mesmo tempo, mantém, quase 25 anos após o surgimento da Ação da Cidadania Contra a Fome, uma parcela da população abaixo da linha da pobreza.

Os movimentos feministas, apesar das discordâncias sobre as táticas para criticar o posicionamento da Marisa, foram eficientes ao apontar a presença das desigualdades de gênero na mídia e mobilizar uma discussão séria sobre corpo, saúde e doença das mulheres. Eles provocaram a resposta da empresa e o debate público em torno do assunto. As ações nas lojas físicas e os artigos na internet indicam o aumento da legitimidade dos argumentos feministas em um país conservador como o Brasil. 0 ativismo feminista no Brasil demonstra, a nosso ver, algum amadurecimento. Ambos, no entanto, publicidade e feminismo, ao conceder visibilidade aos problemas de gênero, contribuem para a discussão de valores e conflitos, avanços e retrocessos do papel da mulher na cultura brasileira hoje.

\section{Financiamento}

Fundação de Amparo à Pesquisa do Estado do Rio de Janeiro (Faperj), Coordenação de Aperfeiçoamento de Pessoal de Nível Superior (Capes) e Conselho Nacional de Pesquisa Conselho Nacional de Desenvolvimento Científico e Tecnológico (CNPq). 


\section{Agradecimentos}

As autoras agradecem as contribuições e críticas dos integrantes do grupo de pesquisa Núcleo de Estudos de Mídia, Emoções e Sociabilidade (Nemes) da UFRJ e do LAC (Laboratório de Antropologia do Consumo) da PUC-Rio.

\section{Referências}

BATISTA, Beatriz Beraldo. Por saias e causas justas: feminismo, comunicação e consumo na Marcha das Vadias. 2014. Dissertação (Mestrado em Comunicação e Práticas de Consumo) - Escola Superior de Propaganda e Marketing, São Paulo, 2014.

BROOKS, Ann. Postfeminisms: feminism, cultural theory and cultural forms. London: Routledge, 2003.

D’ALAMA, Luna. Ativistas do Femen protestam em loja de roupas femininas em BH. G1, Rio de Janeiro, 2012. Disponível em: <http://g1.globo.com/minasgerais/noticia/2012/11/ativistas-do-femen-protestam-em-loja-de-roupas-femininas-embh.html>. Acesso em 19 jan. 2018.

FEMINISTAS do Cariri. Ato de protesto - Grupo Feminista Casa 8 de Março. Facebook, [S.l.], 22 out. 2012. Disponível em:

<https://www.facebook.com/feministasdocariri/photos/a.260269057417323.53080.2360 36689840560/292385347539027/?type=3\&theater>. Acesso em: 19 jan. 2018.

FONTES, Leo. Garotas do Femen quebram Loja Marisa em BH contra comercial. Terra, [S.I.], 2012a.

FONTES, Leo. Imagem 27/52. In: IMAGENS do 11 de novembro de 2012. Uol, [S.l.], 2012b. Disponível em: <http://noticias.uol.com.br/album/album-do-dia/2012/11/11/imagens-dodia---11-de-novembro-de-2012.htm\#fotoNav=27>. Acesso em: 19 jan. 2018.

FOUCAULT, Michel. Vigiar e punir: nascimento da prisão. Petrópolis, Vozes, 1987.

FRIEDAN, Betty. Mística feminina. São Paulo: Vozes, 1971.

GENZ, Stephanie; BRABON, Benjamin. Postfeminism: cultural texts and theories. Edinburgh: Edinburgh University, 2009.

GILL, Rosalind. Advertising and Postfeminism. In: GILL, Rosalind. Gender and media. Cambridge: Polity, 2007. p. 73-112.

GOFFMAN, Erving. Gender advertisements. New York: Harvard University, 1979.

GOLDMAN, Robert; HEATH, Deborah; SMITH, Sharon. Commodity feminism. Critical Studies in Media Communication, London, v. 8, n. 3, p. 333-351, 1991. 
HOMENAGEM. Direção: Felipe Mansur. Criação: Alessandra Pereira. Direção de criação: Luiz Sanches. Trilha sonora: A Voz do Brasil. São Paulo: AlmapBBDO, 2012. Disponível em: <https://www.youtube.com/watch?v=3iKNi8CSIEk>. Acesso em: 15 fev. 2016.

INSTITUTO BRASILEIRO DE EXECUTIVOS DE VAREJO E MERCADO DE CONSUMO. Ranking IBEVAR - 120 maiores empresas do varejo brasileiro [2015]. São Paulo: IBEVAR, 2015.

LAÍS como garota propaganda já. [S.l.]: Activism, 2012. Disponível em:

<https://www.activism.com/pt_BR/peticao/lais-como-garota-propaganda-ja/40046>. Acesso em: 19 jan. 2018.

LIPOVETSKY, Gilles. A terceira mulher: permanência e revolução do feminino. São Paulo: Companhia das Letras, 2000.

MARISA. Institutional presentation 3Q17. São Paulo: Marisa, 2017. Disponível em: <http://ri.marisa.com.br/>. Acesso em: 19 jan. 2018.

MCROBBIE, Angela. Post-Feminism and Popular Culture. Feminist Media Studies, London, v. 4, n. 3, p. 255-264, set. 2004.

PANTENE. Don't hate me because I'm beautiful. 1986. Disponível em:

$<$ https://www.youtube.com/watch?v=jssGyRoC-3w>. Acesso em 19 jan. 2018.

RIOS, Daniela Gil. Marisa - Homenagem. São Paulo: Conar, 2012. Disponível em:

<http://www.conar.org.br/processos/detcaso.php?id=3314>. Acesso em: 27 dez. 2012.

ROCHA, Everardo. Magia e capitalismo: um estudo antropológico da publicidade. São Paulo: Brasiliense, 2010.

SANT'ANNA, Denise. A cultura na ponta do garfo: estética e hábitos alimentares na cidade de São Paulo -1890/1920. Cadernos Pagu, Campinas, v. 39, p. 77-200, 2012.

SANT'ANNA, Denise. Bom para os olhos, bom para o estômago: o espetáculo contemporâneo da alimentação. Pro-Posições, Campinas, v. 14, n. 2, p. 41-52, maio/ago. 2003.

SCOTT, Joan. Gênero: uma categoria útil de análise histórica. New York: Columbia University, 1989.

SOARES-CORREIA, Maria Joana. "Homenagem" Marisa e o corpo na sociedade pós-moderna. In: ENCONTRO NACIONAL DE ESTUDOS DA IMAGEM, 4., 2013, Londrina. Anais... Londrina: UEL, 2013.

SOUZA, Carla Basílio. "De mulher para mulher": representações de gênero em campanhas da varejista Marisa e sua repercussão em ambientes on-line. 2015. Trabalho de Conclusão de Curso (Graduação em Comunicação Social - Publicidade e Propaganda) - Universidade Federal do Rio de Janeiro, Rio de Janeiro, 2015.

TAYLOR, Charles. The ethics of authencity. Cambridge: Harvard University, 1991. 
TELARI, Riva. Marisa empenhada com slogan “De mulher pra mulher... machista!”. Escreva Lola Escreva, [S.l.], 11 nov. 2012. Disponível em:

<http://escrevalolaescreva.blogspot.com.br/2012/11/guest-post-marisa-empenhada-comslogan.html>. Acesso em: 19 jan. 2018.

TOLIPAN, Heloísa. Polêmica: pós-manifesto em BH, mulheres ainda criticam comercial da rede Marisa. Jornal do Brasil, Rio de Janeiro, 12 nov. 2012. Disponível em:

<http://www.jb.com.br/heloisa-tolipan/noticias/2012/11/12/polemica-pos-manifestoem-bh-mulheres-ainda-criticam-comercial-da-rede-marisa/>. Acesso em: 5 mar. 2016.

VIGARELLO, George. Les métamorphoses du gras: histoire de l'obésité. Paris: Du Seuil, 2010.

VOU de Marisa. “Conversa” Marisa. Facebook, [S.l.], 2012. Disponível em:

<https://www.facebook.com/voudemarisa/posts/298848736881841?comment_id=13552

81\&not\%20if\%20_t=like>. Acesso em: 19 jan. 2018.

WOLF, Naomi. 0 mito da beleza: como as imagens de beleza são usadas contra as mulheres. Rio de Janeiro: Rocco, 1992.

\title{
The empowered consumer: advertising, gender and feminism
}

\begin{abstract}
Since the mid-1980s, advertisements, when developing gender representations, incorporate ideals broadly associated with feminism: freedom, autonomy and power. In this article, we present a case study about the advertising called Homenagem (tribute in English), created by Marisa Store, which is the target of intense protests by Femen Brazil and other feminist collectives. In response to protests, the brand broadcasted a video, but did not change its position, which displeased even more the consumers. We describe the narrative structure of the advertising; analyze the media coverage of the case, and the arguments of the protesters, in order to examine the contradictions and ambiguities of both the promotion of consumption and the logic of post-feminist criticism today. The research findings show how Brazilian feminist movements produced a relevant public debate by pointing out the existence of gender inequalities in the media and by creating a discussion about women's body, health, and diseases.
\end{abstract}

\section{Keywords}

Advertising. Gender. Feminism. Post-feminism. Body.

Recebido em 27/06/2017

Aceito em 11/10/2017 